\title{
Stimulus intensity dynamism and generalization of inhibition in a discriminated lever press avoidance situation
}

\author{
JOHN C. BIRKIMER, UNIVERSITY OF LOUISVILLE
} J. P. JAMES, UNIVERSITY OF MANITOBA

Rats were trained in a discriminated lever press avoidance situation in which three intensities of white noise were warning signals and a fourth intensity, the highest, was not followed by shock. After initial performance to this highest intensity stimulus decreased, the typical stimulus intensity dynamism (SID) gradient over the three warning signal intensities did not obtain. When the highest intensity stimulus was then made a warning signal, followed by shock, the usual SID gradient reappeared.

Stimulus intensity dynamism (SID), when used in the descriptive sense (Gray, 1965, pp. 180-181), refers to an observed increase in the probability, magnitude, frequency, and so forth of a learned response as a function of an increase in the intensity of a stimulus which controls the occurrence of the response. Perkins (1953) and Logan (1954) have suggested that the SID effect is interpretable in terms of a generalization of inhibition gradient, centered at unreinforced background or zero intensity, which decreases with increased stimulus intensity. In his review of studies testing the Perkins-Logan hypothesis, Gray (1965) mentioned one of his own studies (unpublished) in which reversal of the usual SID gradient was obtained in a discriminated free operant situation by reinforcing responses made in the presence of all stimulus intensities except the most intense. Theoretically, Gray created an inhibitory gradient centered at the highest intensity stimulus and decreasing over lower intensities, thereby corroborating the Perkins-Logan prediction.

Since Gray's work is unpublished, and since the manipulability of the SID gradient has theoretical relevance, the efficacy of manipulating such gradients by nonreinforcement of the highest intensity stimulus was investigated. A highly reliable SID effect has been demonstrated in a discriminated instrumental avoidance task (Kessen, 1953), so the present study examined the effect of Gray's procedure in that situation.

Method

Four experimentally naive male albino rats, approximately 150 days old, were given avoidance training in an operant conditioning apparatus. Four intensities of white-noise were used as $\mathrm{CSs}\left(\mathrm{CS}_{1}=80 \mathrm{~dB}, \mathrm{CS}_{2}\right.$ $=87 \mathrm{~dB}, \mathrm{CS}_{3}=94 \mathrm{~dB}, \mathrm{CS}_{4}=101 \mathrm{~dB}$; background =73$76 \mathrm{~dB})$. Trials were presented on a variable interval 40-sec schedule (range $=20-60$ sec). A 5-sec inter- stimulus interval (ISI) preceded a $1.3 \mathrm{~mA}$ shock presented on a .2 sec on, $2 \mathrm{sec}$ off repeating cycle.

Ss received $6 \mathrm{~h}$ avoidance training dally with the four CSs presented in essentially random order. During the three phases of the study $\mathrm{CS}_{1}, \mathrm{CS}_{2}$, or $\mathrm{CS}_{3}$ was followed by intermittent shock until $\mathrm{S}$ responded. Responses to these CSs during the ISI terminated the CS immediately and prevented shock. During the first two phases of the study $\mathrm{CS}_{4}$, although not followed by shock, was terminated by a response, or, if no response was made, terminated at the end of the ISI. During the third phase of the study the $\mathrm{CS}_{4}$ procedure was identical to that of the other CSs.

Subjects were run (Phase 1) until the percentage of trials on which $\mathrm{S}$ terminated $\mathrm{CS}_{4}$ dropped below the percentage avoidance to $\mathrm{CS}_{3}$ (indicating the effect of $\mathrm{CS}_{4}$ nonreinforcement) and were continued (Phase 2) until their performance appeared to have been adequately assessed. $\mathrm{CS}_{4}$ was then reinforced (Phase 3) to determine if effects observed during Phase 2 were, in fact, due to nonreinforcement of $\mathrm{CS}_{4}$ and not to possible changes in SID gradients with continued training.

Analysis was made in terms of inversions from the usual SID gradient. An inversion was defined as a lower percentage avoidance to the higher intensity of two adjacent CSs for a given $S$ on a single day. Results and Discussion

Usual SID gradients were obtained until the effect of nonreinforcement of $\mathrm{CS}_{4}$ appeared. Section 1 of Table 1 shows the proportion of days in Phase 1 on which reversals of the usual SID gradients were obtained for each $S$ and for both pairs of adjacent warning signal intensities. The numerator in these proportions shows the number of days on which a reversal occurred to the two CSs and the denominator indicates the number of days $S$ was run before the effect of $\mathrm{CS}_{4}$ nonreinforcement was evident.

The Perkins-Logan hypothesis suggests that, during Phase 2, inhibition conditioned to $\mathrm{CS}_{4}$ should generalize to lower intensity CSs, increasing the number of reversals of the typical SID gradient.

To test this hypothesis of increased number of reversals, the average proportion of reversals across Ss during Phase 1 was calculated and used as an expected reversal rate. This reversal rate is equal to .15. The probabilities of the observed number or a greater number of reversals over the number of 
Table 1. Proportion of inversions of SID gradients between successive CS intensities for each of four Ss during Phases 1, 2, \& 3, and probabilities of the observed or a greater number of inversions during Phases $2 \& 3$.

\begin{tabular}{|c|c|c|c|c|c|}
\hline & & & Subje & umber & \\
\hline Section & & 1 & 2 & 3 & 4 \\
\hline 1) Proportio & ions, & & & & \\
\hline Phase I & $C S_{1}-C_{2}$ & $1 / 2$ & $1 / 4$ & $0 / 5$ & $0 / 1$ \\
\hline & $\mathrm{CS}_{2}-\mathrm{CS}_{3}$ & $1 / 2$ & $0 / 4$ & $0 / 5$ & $0 / 1$ \\
\hline 2) Proportio & ions, & & & & \\
\hline Phase 2 & $\mathrm{CS}_{1} \cdot \mathrm{CS}_{2}$ & $0 / 11$ & $1 / 9$ & $0 / 22$ & $2 / 16$ \\
\hline & $\mathrm{CS}_{2}-\mathrm{CS}_{3}$ & $1 / 11$ & $4 / 9$ & $11 / 22$ & $10 / 16$ \\
\hline 3) Probabil & ersions, & & & & \\
\hline Phase 2 & $\mathrm{CS}_{1} \cdot \mathrm{CS}_{2}$ & 1.0 & .74 & 1.0 & .69 \\
\hline & $\mathrm{CS}_{2}-\mathrm{CS}_{3}$ & .81 & .04 & $<.001$ & $<.001$ \\
\hline 4) Proportio & Ions, & & & & \\
\hline Phase 3 & $\mathrm{CS}_{1}-\mathrm{CS}_{2}$ & $0 / 3$ & $0 / 3$ & $0 / 17$ & $0 / 4$ \\
\hline & $\mathrm{CS}_{2}-\mathrm{CS}_{3}$ & $0 / 3$ & $0 / 3$ & $5 / 17$ & $1 / 4$ \\
\hline 5) Probabili & ersions, & & & & \\
\hline Phase 3 & $\mathrm{CS}_{1}-\mathrm{CS}_{2}$ & 1.0 & 1.0 & 1.0 & 1.0 \\
\hline & $\mathrm{CS}_{2}-\mathrm{CS}_{3}$ & 1.0 & 1.0 & .11 & .45 \\
\hline
\end{tabular}

days run in Phase 2 for a given $S$ between a given pair of CSs was then determined by using the binomial expansion and obtaining $\sum_{r}^{n} C_{r}^{n} p^{r} q^{(n-r)}$ with $n$ the number of days $S$ was run in Phase 2, $x$ the observed number of reversals, $p$ the expected reversal rate .15 , and $q$ simply $(1-p)$. Sections 2 and 3 of Table 1 show, respectively, the observed proportion of reversals and the probability of the observed or a greater number of reversals, for each $\mathrm{S}$ in Phase 2.

To obtain a group test of the Perkins-Logan prediction of an increase in number of inversions in Phase 2, the obtained probabilities for Ss were combined by the method suggested by Winer (1962, pp 43-44; $x^{2}=2 \sum_{i=1}^{n}\left(-1 n p_{i}\right)$ and $\left.d f=2 n\right)$. A $x^{2}=34.484$ $(d f=8)$ was obtained for number of reversals between $\mathrm{CS}_{2}$ and $\mathrm{CS}_{3}$, with a $\mathrm{p}<.001$ under the null hypothesis, indicating an increase in number of reversals between these two CSs during Phase 2. A $X^{2}=1.344(\mathrm{df}=8)$ was found for number of reversals between $\mathrm{CS}_{1}$ and $\mathrm{CS}_{2}$, quite likely under the null hypothesis of no increase in number of reversals.
For Phase 3, with $\mathrm{CS}_{4}$ reinforced, Sections 4 and 5 of Table 1 show the observed proportion of reversals and the probability of the observed or a greater number of reversals, as calculated above, for each $S$. $\mathrm{X}^{2}$ calculated on the probabilities of the observed or a greater number of reversals between $\mathrm{CS}_{2}$ and $\mathrm{CS}_{3}$ yielded a value of $6.012(\mathrm{df}=8, \mathrm{p} \approx .64)$, and no $\mathrm{S}$ showed reversals between $\mathrm{CS}_{1}$ and $\mathrm{CS}_{2}$ during this phase. Thus, the data from Phase 3 are quite consistent with the null hypothesis of no increase above Phase 1 reversal rate.

The results, then, indicate an increase in the number of inversions of the SID gradient between $\mathrm{CS}_{2}$ and $\mathrm{CS}_{3}$ after the effect of $\mathrm{CS}_{4}$ nonreinforcement appeared, and a return to the earlier reversal rate after $\mathrm{CS}_{4}$ reinforcement was begun. Similar changes in number of inversions did not occur between $\mathrm{CS}_{1}$ and $\mathrm{CS}_{2}$.

These results support the Perkins-Logan hypothesis, indicating that inhibition can generalize along a stimulus intensity dimension and, if conditioned to high intensity stimuli, lead to increased inversions in observed SID gradients. That no such change in reversal rate occurred between $\mathrm{CS}_{1}$ and $\mathrm{CS}_{2}$ suggests, perhaps, that inhibitory effects generalizing from $\mathrm{CS}_{4}$ to $\mathrm{CS}_{2}$ were too weak to override inhibition generalizing from the unreinforced background intensity. Such a result follows from the assumption of concave upward generalization of inhibition gradients, of the type found by Hovland (1937) for generalization of inhibition and by Guttman \& Kalish (1956) for generalization of excitation.

\section{References}

Gray, J. A. Stimulus intensity dynamism. Psychol. Bull., 1965, 63, 180- 196.

Guttman, N., \& Kalish, H. I. Discriminability and stimulus generalization. J. exp. Psychol., 1956, 51, 79-88.

Hovland, C. I. The generalization of conditioned responses. I. The sensory generalization of conditioned responses with varying frequencies of tone. J. gen. Psychol., 1937, 17, 125-148.

Logan, F. A. A note on stimulus intensity dynamism (V). Psychol. Rev., 1954, 61, 77-80.

Perkins, C. C., Jr. The relation between conditioned stimulus intensity and response strength. $J$. exp. Psychol., 1953, 46, 225-231.

Winer, B. J. Statistical principles in experimental design. New York: McGraw-Hill, 1962. 